In The Wealth of Nations, Smith argued that economies should be consumer-driven, not producer-controlled. He exposed the old mercantilist system - in which a nation's prosperity was assumed to depend on its assets - as mere economic tribalism and industry protectionism. "The wealth of a country consists, not of its gold and silver only, but in its lands, houses, and consumable goods of all different kinds," Smith wrote. Ridley agrees: in the long run, what counts is how consumers prosper by obtaining high-quality products at low prices. He notes that of the people designated as 'poor' who live in industrialized Western nations today, $99 \%$ have electricity, running water, a refrigerator and flushing toilets.

The Rational Optimist dovetails well with The Wealth of Nations and with The Science of
Liberty in demonstrating that where people are free to trade in the broadest sense - including the free exchange of everything from genes to ideas - prosperity ineluctably follows.

Michael Shermer is publisher of Skeptic magazine and adjunct professor of economics at Claremont Graduate University, Claremont, California 91711, USA. He is the author of The Mind of the Market. e-mail: mshermer@skeptic.com

\title{
A flowering of pleasure and pain
}

\section{The latest collaborative artwork from neuroscientist Morten Kringelbach and artist Annie Cattrell reveals - and revels in — sensory dialogues in the brain, explains Martin Kemp.}

Why is the neuroscientist Morten Kringelbach exhibiting in an art gallery a photograph of a dried globe amaranth (Gomphrena globosa) unfolding in a glass teapot on a scenic balcony? His mysterious picture accompanies a sculpture of brain connectivity made by Kringelbach's collaborator, the Scottish artist Annie Cattrell. It seems here as if the scientist is acting like an artist and the artist like a scientist. But this framing is wrong; our terms of reference are too crude.

For an explanation, we must look at the history of the developing collaboration between Kringelbach and Cattrell (see Nature 424, 18; 2003). During Cattrell's highly productive residency at the Royal Institution in 2002, she worked with the neuroscientist's data to model, in three dimensions, the zone of brain activity that corresponds to the stimulation of each of the five senses. She cast the shape of each sensory zone in resin and mounted them in five crystalline cubes to create the artwork Sense.

The intellectual and visual traffic in their collaboration was not all one-way. Cattrell's translation of data into sculptures made some of the neurological issues appear differently to Kringelbach. His involvement with the making of Sense confirmed to him that sensory identification precedes and is not modified by hedonic (pleasure-orientated) processing. The collaboration heightened his concern with questions about the vital contextualizing activities that occur below the threshold of brain monitoring. What determines how judgement, subjective experience and decision-making occur on the basis of sensory input?

Their new sculpture Pleasure/Pain - which I deliberately attribute to both of them - models the structural connections of a small region in the brainstem, the periaqueductal grey, as revealed by a method of magnetic resonance imaging called diffusion tensor imaging. The piece explores the links that might be activated during sensations of pleasure and pain. The periaqueductal grey is a pivotal and primitive

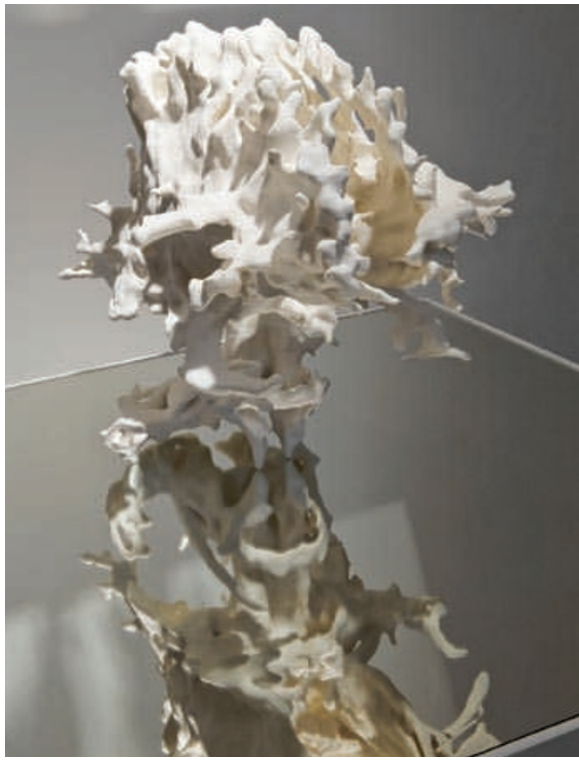

area of the brainstem that functions in ways that are incompletely understood.

Low frequencies applied to the periaqueductal grey during deep-brain stimulation relieve chronic pain; higher frequencies enhance the pain. The region works with other areas of the brain through a reciprocal call-and-response mechanism. Oscillations of neural activity bounce back and forth, moving at different frequencies, some initiating pain, others moderating it. As Kringelbach explains, "what is key is that the sender and recipient neurons - like two girls rhythmically swinging a jump rope for a third to hop over - must be in sync."

Cattrell created the model of this oscillating connectivity using a rapid prototyping method called selective laser sintering. It is a kind of sculptural photocopying in which cross-sectional layers are fused to create a solid model. Delicate traces of the successive layers can be detected on the surface of the sculpture, like contour lines on a map. The resultant shape invites analogies - an incredibly complicated

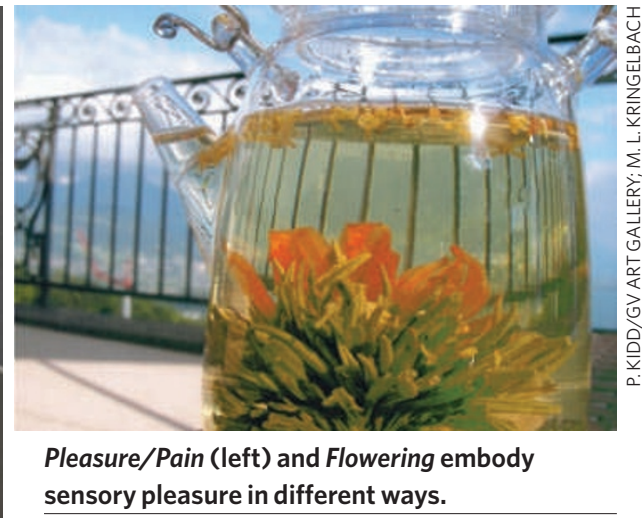

vertebra perhaps, or a wondrous fungal growth, or even a blossom flowering posthumously in the scalding water of a teapot.

It is within the shared openness of the sculpture and the photo that our crude premises break down. The model of the connections of the periaqueductal grey does not record a set structure, but rather the potential pathways of a dialogue - one that may blossom to induce pleasure or surge back and forth to produce pain. There is uncertainty both in the process and in our understanding of it. The intricate, visually delicate and evanescent form of the sculpture embodies hedonic potentials and plots aspects of the fuzzily understood.

In Flowering, the image of brewing tea exudes a promise of sensory pleasure both in itself and in its setting. The Sun slants across a balcony set high above blue hills. The pleasure passes beyond the visual, evoking the exhilarating aroma and fragrant taste of the refreshing tea.

Cattrell and Kringelbach are telling us that art can be as rationally founded as Renaissance theorists insisted, and that science can be as suggestively open as the act of looking itself. Martin Kemp is emeritus professor in the history of art at the University of Oxford, Oxford, UK. 